\title{
Explaining, Cultural, Educational and Social Needs of Faculty Members of Farhangiyan University
}

(according to the predetermined goals of Education's fundamental transformation document) ${ }^{1}$

Batool Basiri (Corresponding Author)

Dept. of Curriculum, University of Isfahan

Tel: 98-913-304-0848Ｅ-mail: b_basiry@yahoo.com

Ahmadreza Nasr

Dept. of Curriculum, University of Isfahan

Tel: 98-913-128-7504Ｅ-mail: arnasr@edu.ui.ac.ir

Seyed Ebrahim Mirshahjafari

Dept. of Curriculum, University of Isfahan

Tel: 98-913-116-1384Ｅ-mail: jafari@edu.ui.ac.ir

Mahmood Mehrmohammadi

Dept. of Curriculum, Tarbiat Modares University

Tel: 98-912-103-9032Ｅ-mail: mehrmohammadi_tmu@hotmail.com

Received: May 5, 2015 Accepted: June 24, 2015 Published: August 1, 2015

doi:10.5296/jse.v5i3.7541ＵRL:http://dx.doi.org/10.5296/jse.v5i3.7541

\begin{abstract}
${ }^{1}$ This study has been conducted under the auspices and the support of Farhangian University.
\end{abstract}

The present study is an applied research project and uses a descriptive-analytical survey design. It follows both qualitative and quantitative data collection procedures. The statistical 
population of the qualitative section consists of 19 Iranian education experts who are selected via targeted random sampling. And the statistical population of the quantitative section consists of all full-time instructors and faculty members of Farhangian University in six provinces of Iran $(n=181)$, of whom 150 are selected via random sampling. Data are collected through semi-structured interviews and researcher-made questionnaires. To determine the validity of interviews and questionnaires, we have used confirmatory factor analysis for verifying construct validity and Cronbach's alpha for estimating questionnaire reliability. Qualitative findings are analyzed based on the spiral of analysis and quantitative data are processed through descriptive and inferential statistics. According to the results of the qualitative section, the most important educational needs of Farhangian University's faculty members fir into two areas: 1. Religious needs with an emphasis on Islamic education, and 2. ethical, cultural and social needs comprising four domains: 2.1 cultural, 2.2 social, 2.3 ethical, and 2.4 political. The results of the quantitative section also indicate that the educational needs of Farhangian University's faculty members are higher than average in both areas. The most important need of Farhangian University's faculty members in the cultural domain is related to the subscale "being aware of the role of university professors in relation to preserving, transferring, reforming, and recreating culture" while their most important need in the theological domain is related to "the ability to use the educational principles and implications of the Quran and Nahjolbalaghe” (Imam Ali's book of ethical teachings)

Keywords: Needs assessment, cultural needs, social needs, educational needs, faculty members, analyzing 


\section{Introduction}

Changes and developments that occur to cultures and cultural systems over time lead to new needs and goals in any society (Chalabi, 1996:22-245). In any community, universities have a huge responsibility including the preservation and transmission of the cultural heritage and the reinforcement of moral and social principles in students (Taherpour, Rajaipour, and Shahbazi, 2009). Regarding the educational mission of Farhangian University in the field of cultural education, the growing cultural, educational, and social expectations of student-teachers require effective planning for the achievement of a desirable status. The first step will be to identify the current situation through educational needs assessment which currently is considered as one of the most important prerequisites of planning in the field of higher education. Considering the applied nature of the knowledge of student-teachers in Farhangian University and their unmediated entrance into the field of education, analyzing and explaining the educational needs of teachers become highly important and necessary. For this reason, the aim of the present study is to analyze and explain the cultural, educational, and social needs of Farhangian University's faculty members as a very influential stratum in training the next generation of the Islamic Republic of Iran via educational needs assessment. In order to examine the existing literature, the researchers reviewed relevant studies conducted both inside and outside Iran.

The results of a study by Mahdavi (1999) point to numerous cultural problems among young people. In this regard, universities must be able to make students internalize cultural norms and attitudes. According to Mirzaee (2002), although the cultural attitude of students confirms the entirety of religious beliefs and emotions in the academia, it represents the growth of a new mode of religious thinking that seeks to undermine the role of religion in society. According to Movahedi (2004), the use of non-local development strategies and patterns has failed in many societies, especially in developing countries, since development strategies and models must comply with the indigenous culture of any society. Vahed Chukadeh (2005) refers to the pivotal role of universities in cultural education and avers that educational courses must be designed in a way as to propagate and promote proper cultural and social education (15). Fathi Vajargah et al. (2006) believe that integrating cultural values in education at various levels is a vital necessity (32). Some researchers believe that young people are very vulnerable to cultural issues. That is why they all have put cultural needs in priority (Hamidi, 2005, Ahmadi et al., 2008; Esmaeeli and Rabiee, 2008, Osareh et al., 2012). Shamshiri (2008) also argues that the revision of educational issues several years after the revolution shows that not much success has been achieved despite the efforts of Islamic Republic of Iran's Ministry of Education (63). According to Kazemi (2010), the performance of educational leaders in educating audiences for entering a value system based on spirituality, integrity and community has failed (p 35). Loqmannia and Khamesan (2010) also argue that the weakness of educational institutions in relation to cultural identity is rooted in irrelevant curriculum contents on various ethnic groups and subcultures and the concept of a multiple national and cultural identity. Saboktakin and Khosrojari (2013) argue that mere education is pointless. Rather, education also includes cultural education (55). Other researchers believe that a knowledge-based culture should be the basis for higher education in order to facilitate 
innovation and creativity in higher education (Safaee and Fakhri, 2013:5). According to some researchers, higher education centers as the community of scholars and elites can play a more effective role in social, political, and cultural development and, in general, in the accomplishment of the country's cultural mission in line with an Iranian-Islamic identity (Monafi Sharafabad and Zamani, 2013, 58). Other related studies (1996-2009) have introduced the following factors as the points of weakness in Iran's higher education system in relation to cultural education and national identity. These include:

A) The weakness of educational institutions with regard to the Iranian culture and the absorption of foreign cultures (Kaffash and Faridi, 1996, p12' and Tavakkoli Nik, 2001).

B) Unsatisfactory curriculum with regard to identity formation in individual, social and national areas (Rabbani, 2003, 65).

C) Incompatibility between Islamic, historical, geographic and global identities (Rabbani, 2003).

D) Disagreement on a cultural-national identity, which has decreased the possibility of considering and strengthening it in the curriculum (Loqmannia, 2009:171).

The overall aim of any educational system in the world is to meet the demands and consider the ultimate purpose of its society. As the most important institution in the transmission of cultural values, schools and universities must develop social and cultural behaviors along with their training and educational purposes (Zokaee, 2003:53). It seems that higher education can take positive steps in this field only when it pays special attention to its curricula - whether official or unofficial (Sharafi and Taherpour, 2008:26). In fact, curricula with a traditional approach to the transmission of culture focus on certain prescribed cultural values for the development of behavioral and national characteristics (Gutek, translated by Pakseresht, 2007:78). However, according to Delanty (2007), the ideal form of cultural education consists of an open university which is marked by features different from those of a traditional university. Shifting from course-based, department-based, subject-oriented, and knowledge-centered systems of higher education to credit-based, program-based, learning/student-oriented, and proficiency-centered systems is the hallmark of transition from a traditional to a modern model of education (Delanty, 2007:258-259).

In the same line, studies conducted in other countries are also inspiring. For example, the results show that considering socio-cultural needs and valuing different cultures are a significant cultural need and that cultural, social, and political knowledge is highly correlated with current university curricula (Lee Kuang Wu, 2000; An Ran and Viv Edward, 2006; Terry Green, 2008; Brendan Bartaram, 2009; Riveilli, 2010; Reynher, Gillbert and Lockard, 2011). Jang (2009), as quoted by Kallen (2001), also argues that internationalizing curricula in universities produces certain cultural and educational opportunities and that confronting other cultures will lead to the acquisition of knowledge and experiences which could never be acquired otherwise (quoted by Jang, 2009). Sikart (2008) also avers that the globalization phenomenon influences the national and cultural identity of faculty members in its different aspects. Fass and Ross (2012) argue that there is no convergence between the cultural contents of experienced and performed curricula - what leads to many questions in relation to the cultural and national needs of the education system. The results of a study by Beuckelaer 
et al. (2012) show that the existence of cultural variety is a positive and valuable potential for improving the educational quality and efficiency of faculty members. Finally, the results of another study by Leedjia Svec (2014) show that cultural knowledge enables the individual or the organization to save resources, improve living conditions, and accomplish responsibilities.

Generally, we can conclude that cultural education or internalization is one of the responsibilities of university faculty members by which cultural meanings are incorporated into the self. In fact, universities are the most valuable resources available to any society for cultural progress and development. Among the building blocks of universities, professors are considered as key factors of progress. The consideration of their educational needs is a priority in Iran's developmental Prospect Document. In order to achieve this objective, Farhangian University must turn into an active center for fighting against old training habits which are sometimes even harmful and, considering the formation of new cultural needs and expectations in society, pursue a new form of cultural management in order to prepare future university professors for accepting their educational and cultural role outside the confines of old training patterns and procedures.

In the words of Mehrmohamadi (2013) "teaching is a main and extensive activity in universities, especially in Farhangian University, and one of its important dimensions is based on the cultural, educational, and social needs of student- educator curricula. Thus, if it is expected that educational programs pave the way for this purpose, we must realize that one of the most important domains in this regard is the training of educators so they can achieve mastery, intellectual discipline, and competency in the field" (Mehrmohamadi, Interview, 2013). The need to consider these issues convinced the researchers to assess the needs of faculty members in the field of cultural, educational, and social activities. It must be noted that the By-law on Promotion of Faculty Members of Farhangian University considers four main activities: a) cultural, educational and social activities, b) training activities, c) research and technological activities, and d) scientific and executive activities (The By-law on Promotion of Faculty Members, 2011). The present study therefore considers only the first category of activities - namely cultural, educational, and social activities - in two subsidiary domains: 1) Theological knowledge with an emphasis on Islamic education, and 2) ethical, cultural and social issues.

\section{Methodology}

\subsection{Research Typology}

The present study uses a descriptive-analytical surveying design. Depending on the object of inquiry in different sections, the study employs both qualitative and quantitative data collection methods. Qualitative methods are used for collecting information about the educational needs of Farhangian University's faculty members from education specialists and authorities whereas quantitative methods are employed for collecting information from full-time instructors and faculty members of Farhangian University. The findings of the qualitative section are used not only for answering the research questions but also for developing a quantitative data collection instrument. After transcribing the interviews, we 
extracted the basic subscales related to the two domains of Theological knowledge and ethical, cultural and social issues and incorporated them into the questionnaire. As a result, the present study uses a combinational exploratory approach (Plano Clark, et al. 2008:372; Creswell and Plano Clark, 2007:62-72 quoted by Sharifian et al. 2013:54).

\subsection{Statistical Population and Sample}

The statistical population of this study is comprised of two groups: a) Iranian education experts and authorities - we ran semi-structured interviews with 19 education experts and authorities who compose the study sample of the qualitative section; and b) all full-time instructors and faculty members of Farhangian University who form the study sample of the quantitative section - samples were taken from the four poles of Iran, including Isfahan, Chaharmahal and Bakhtiari, Lorestan, Yazd, Khuzestan, and Ilam provinces. The present study initially used targeted sampling method for the selection of educational experts and authorities (Creswell, 2007). In fact, the experts and authorities selected as the study population were "significant samples" (Williams, 2006:79). In addition to targeted sampling, we also used snowball sampling method during the interviews (Noori, 2008:330). The first interviewees were asked to recommend those whom they considered competent for the topic of the interview. The size of the sample from educational experts was not calculated quantitatively since very small or large samples are not recommended for qualitative studies and such criteria as data saturation and information redundancy show the adequacy of the sample (Onwuegbuzie and Leech, 2007:242; Guest et al. 2006:59 quoted by Sharifian et al. 2013:54). We also used stratified random sampling for the selection of full-time instructors and faculty members of Farhangian University so that all full-time instructors and faculty members from selected provinces were incorporated into the sample. The sample of the quantitative section of this study is composed of 150 full-time instructors and faculty members. 45 of them (30.6\%) had a $\mathrm{PhD}, 102$ had an MA/MS (69.4\%), and three had an unspecified degree. The sample size was calculated via different methods. In the first method, we used Cochran's sample size formula to specify the number of instructors and faculty members $(n=123)$. Additionally, after performing the study, we calculated the power of the test's statistical power $(=1)$ and verified the adequacy of the sample.

\subsection{Data Collection Instruments and Determining their Validity and Reliability}

The present study uses a semi-structured interview and a researcher-made questionnaire. The researchers interviewed the experts on their perspectives concerning the topic. The validity of the interview was considered and confirmed by the respondents. The reliability of the questionnaire form was examined by three knowledgeable experts in the field of qualitative research methods. They studied the summery of issues and determined categories with the triangulation method (comparing the results of the interview and the questionnaire). Since there were no standardized questionnaires on the research subject, we used a researcher-made questionnaire to collect data from the intended sample. In order to determine the content validity of the interview and the questionnaire, we surveyed the views of 12 faculty members of Isfahan University's Faculty of Education and Psychology who enjoyed the required specialty. The Cronbach's Alpha was deployed for estimating the reliability and internal 
consistency of questionnaire items.

Initial studies on 36 respondents from the sample population and analyses of the questionnaire showed that the first domain, i.e., Theological knowledge, has a reliability of $91.6 \%$ and the second domain, i.e., ethical, cultural, and social issues, has a reliability of 91.3\%. Confirmatory factor analysis and the Varimax rotation procedure were employed for analyzing the construct validity of the items. Therefore, the number of the subscales and the items remained unchanged. A minimum factorial load of 0.4 was the criterion for the subscales to remain in the questionnaire. The results of the KMO test $(=0.900)$ and Bartlett's sphericity test $(=742.144)$ in the domain of "Theological knowledge with an emphasis on Islamic education" were significant and satisfactory $(\mathrm{P}<0.01)$. Similarly, The results of the KMO test $(=0.887)$ and Bartlett's sphericity test $(=459.058)$ in the domain of "ethical, cultural, and social issues" were significant and satisfactory $(\mathrm{P}<0.01)$. Explainable special values and variances were equal to 83.338 and 7.505 , respectively, for the domain of "Theological knowledge with an emphasis on Islamic education" and 75.750 and 7.575, respectively, for the domain of "ethical, cultural, and social issues".

\subsection{Data Collection and Analysis Procedures}

Several procedures exist for the analysis of data extracted from interviews through which we can investigate the statements and views of interviewees (Creswell, 2007:144-177; Campbell et al., 2004:125-147; and Mason 2002:91-96). Normally, there are several stages or steps for analyzing the data collected via from interviews, including data preparation, data organization, data reduction in the form of categories via data codification and condensation, and finally, data presentation in the form of images, tables, or discussions (Creswell, 2007:148). The present study also follows these stages of data analysis. The interviews were performed in person and using a recorder. Then, the interviews were transcribed and typeset. After that, data categorization was performed with the MAXQDA Software Program. Finally, the researchers verified the reliability and presented the findings in the form of tables and discussions. In order to collect the required data, the researchers administered the questionnaires among the faculty members either in person or via post or electronic mail. 150 copies were collected. The researchers employed descriptive and inferential statistical analyses to analyze investigate qualitative data. Descriptive statistical analyses included mean values and frequency. Also, inferential statistical analyses included the normal distribution of data and homogeneity of variance. The researchers deployed parametric tests when the data were characterized by these two specifications. Otherwise, non-parametric tests were used. The tests used in this study include multi-way analysis of variance, factor analysis, and single-variable $t$ test with a hypothetical mean value equal to three. Since the questionnaire items were rated on a five-point Likert scale from one to five, three was set as the middle point.

\section{Findings}

Insofar as the present study uses a combinational (qualitative-quantitative) approach, qualitative and quantitative findings are therefore presented separately based on the research questions. In the qualitative section, the data are analyzed via the categorization method based on qualitative data analysis procedures. After transcribing the 19 interviews, the 
researchers analyzed the statements several times and extracted all significant statements from each questionnaire. In what follows, stated and extracted categories and statements in relation to the two domains mentioned above are presented in Table 1.

Table 1. Prior cultural, educational, and social needs expressed by interviewees

\begin{tabular}{|c|c|}
\hline Main Categories & Prior Educational Needs \\
\hline $\begin{array}{l}\text { A) Theological knowledge } \\
\text { with an emphasis on } \\
\text { Islamic education }\end{array}$ & $\begin{array}{l}\text { 1. The need for learning the Quran in order to answer the } \\
\text { questions of student-teachers } \\
\text { 2. The ability to transfer religious ideas and values and to } \\
\text { inspire strong faith in Islam } \\
\text { 3. Familiarity with rich Islamic resources (Nahjolbalaghe, } \\
\text { Nahjolfesaheh, and other valid Islamic narratives, texts, and } \\
\text { resources) } \\
\text { 4. The ability to understand and extract educational implications } \\
\text { from Islamic recourses } \\
\text { 5. Familiarity with the philosophy of Islamic education } \\
\text { 6. Familiarity with religious objectives in student-teacher } \\
\text { curricula }\end{array}$ \\
\hline & $\begin{array}{l}\text { A) The Cultural Domain } \\
\text { 1. Familiarity with the role of university professors in } \\
\text { preserving, transferring, reforming, and recreating culture. } \\
\text { 2. Basic familiarity with the humanities (sociology, history, art, } \\
\text { philosophy and social science). } \\
\text { 3. Familiarity with comparative education in order to study } \\
\text { other cultures. } \\
\text { 4. The need for internationalizing the curricula. } \\
\text { 5. Familiarity with the principles and objectives of cultural } \\
\text { direction in Iran's Ministry of Education's Fundamental } \\
\text { Development Prospect Document. } \\
\text { 6. Recognizing and exposing the signs of cultural invasion. } \\
\text { 7. The ability to adjust the educational content of textbooks with } \\
\text { religious and cultural resources } \\
\text { 8. Familiarity with the objectives of student-teacher curricula in } \\
\text { cultural, social, and educational issues. } \\
\text { B) The Social Domain }\end{array}$ \\
\hline $\begin{array}{l}\text { B) Ethical, cultural, and } \\
\text { social issues }\end{array}$ & $\begin{array}{l}\text { 1. Recognizing the mission of Farhangian University as a major } \\
\text { center for education } \\
\text { 2. The need for internationalizing the curricula }\end{array}$ \\
\hline
\end{tabular}




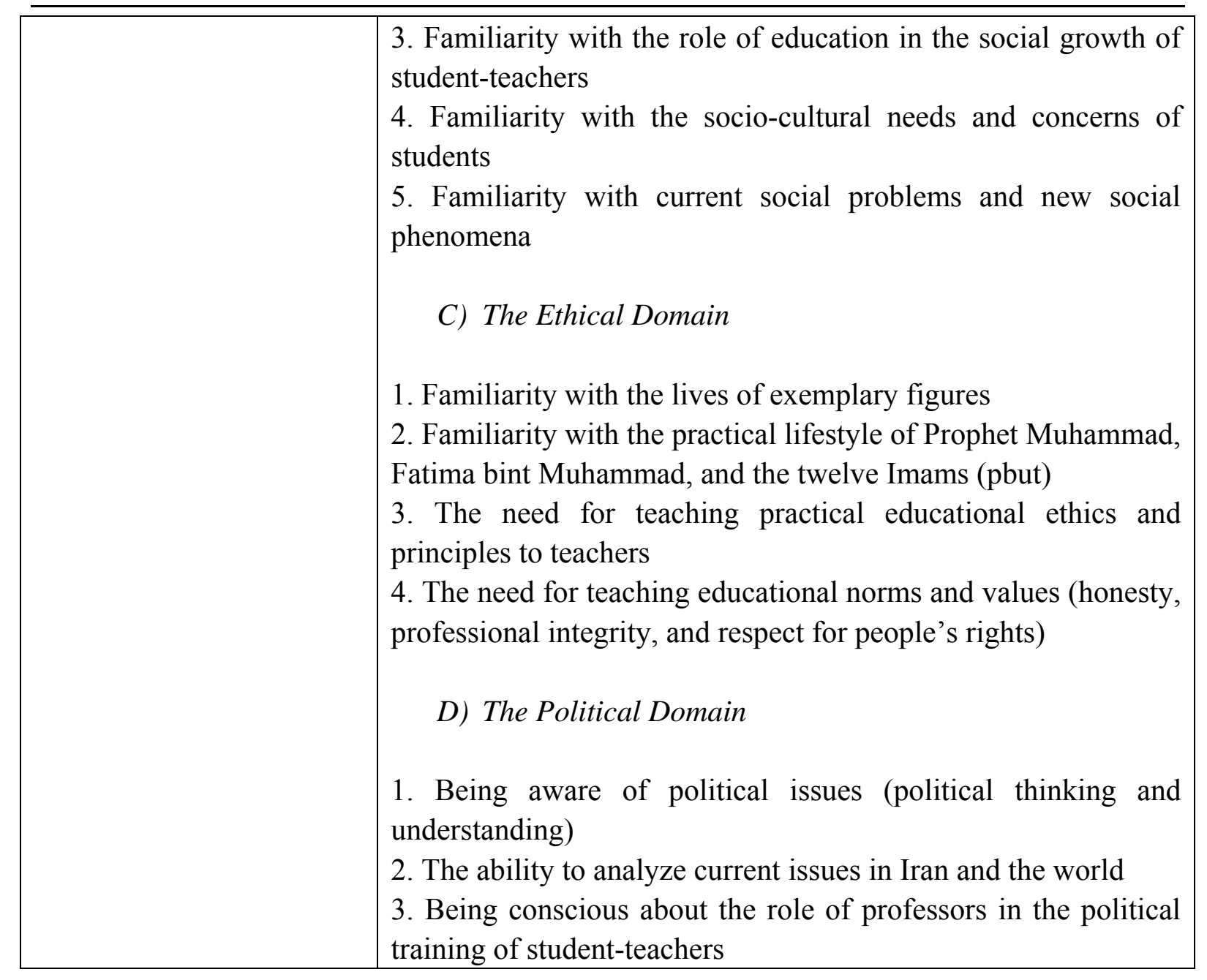

3.1 Research Question 1: What are the educational needs of Farhangian University's faculty members in the domain of theological knowledge with an emphasis on Islamic education?

According to interviewees, six educational needs presented in table 1 are among the most important needs of Farhangian University's faculty members. In what follows, these six items are presented with a brief summary.

3.1.1. The need for learning the Quran in order to answer the questions of student-teachers: 14 respondents $(73.68 \%)$ emphasized this need in the course of the study. Interviewee 1 believed that religious questions are usually proposed by students in various classes. Also, considering rapid socio-cultural transformations, university professors must be able to answer such questions (Interviewee 2). A main point which deserves special consideration is that we must look for teachers who truly believe in religion to appoint them as religious teachers since there is a difference between "knowing about a religion" and "believing in a religion". Education can impart knowledge about a religion but not necessarily guarantee faith in that religion. In fact, teachers must have the knowledge and skills to be able to educate students who have strong faith (Interviewee 13) 
3.1.2. The ability to transfer religious ideas and values and to inspire strong faith in Islam among student-teachers:

12 respondents $(63.15 \%)$ emphasized this need in the course of the study. In general, values become internalized when they are established in the educational system of a country (interviewee 3). As a result, knowing and observing these values must be the first priority for those who are to work in the field of education. It is also recommended that religious consultancy be defined as a permanent position in this university in order to provide answers to the questions of student-teachers (Interviewee 4).

\subsubsection{Familiarity with educational implications and methods in rich Islamic resources:}

Interview 6 believed that Islamic educational implications and methods must be extracted from Islamic resources and be subsequently made available to university professors. When professors have access to rich Islamic educational methods, they can be expected to impart such knowledge to their students.

\subsubsection{Familiarity with the philosophical principles of Islamic education:}

According to 12 interviewees $(63.15 \%)$, one of the most basic things that a teacher must acquire both in theory and in practice is the philosophical principals and objectives of education in the Islamic republic of Iran (Interviewees 6, 9, and 17).

3.1.5. Familiarity with religious objectives in student-teacher curricula and the spirit of Islamic knowledge in teaching:

12 interviewees (63.15\%) deemed it necessary that Fahangian University's professors be familiar with religious teachings practically because theoretical knowledge cannot be enough. Iran's Ministry of Education's Fundamental Development Prospect Document stipulates the proProspect Document of education on the basis of religious teachings (Interviewee 12).

\subsubsection{Familiarity with pure Islamic concepts:}

Five interviewees $(26.31 \%)$ explicitly referred to this need in the course of the study. Interviewee 7 believed that neglecting pure Islamic concepts have resulted in the formation of fake religious concepts. When pure Islamic concepts are extracted from Nahjolbalaghe, Sahifa Sajjadiya, and the Sira of the Infallible Imams and are subsequently included in university courses, such fake teachings will be practically terminated.

3.2 Research Question 2: To what extent do Farhangian University's faculty members require training in the domain of "theological knowledge with an emphasis on Islamic education?

Based on the findings, 64.1 percent of the respondents in the quantitative section had an MA degree and 34.4 percent had a $\mathrm{PhD}$ degree, 57.7 percent were male and 39.7 percent were female, and 46.2 percent of the respondents had a work experience of between 21 and 30 years. 


\section{Al Macrothink}

Journal of Studies in Education

ISSN 2162-6952

2015, Vol. 5, No. 3

Table 2. Comparison of the mean need of Farhangian University's faculty members for receiving training in the domain of "theological knowledge with an emphasis on Islamic education" with a hypothetical mean value equal to three

\begin{tabular}{|c|c|c|c|c|c|c|}
\hline Factor & Mean & $\begin{array}{c}\text { Standard } \\
\text { deviation }\end{array}$ & $\begin{array}{c}\text { Mean } \\
\text { deviation }\end{array}$ & $\mathrm{t}$ & $\mathrm{df}$ & Sig \\
\hline $\begin{array}{l}\text { The need for receiving } \\
\text { training in the domain of } \\
\text { "theological knowledge" }\end{array}$ & 3.61 & 0.83 & 0.069 & 8.882 & 143 & 0.001 \\
\hline
\end{tabular}

According to Table 2, the mean need of Farhangian University's faculty members for receiving training in the domain of theological knowledge with an emphasis on Islamic education is equal to 3.61. Since the calculated t value is higher than the criterion $t$ value, the need for receiving training in this domain can be assessed as higher than average.

3.3 Research Question 3: What are the most important needs of Farhangian University's faculty members in the domain of "theological knowledge with an emphasis on Islamic education"?

Table 3. The most important needs of Farhangian University's faculty members in the domain of "theological knowledge"

\begin{tabular}{|l|l|l|}
\hline & Questions & Mean \\
\hline 1 & $\begin{array}{l}\text { The ability to apply educational methods and implications existing in the Quran } \\
\text { and Nahjolbalaghe }\end{array}$ & 5.66 \\
\hline 2 & $\begin{array}{l}\text { Learning the Quran and Nahjolbalaghe in order to answer the questions of } \\
\text { today's student-teachers }\end{array}$ & 5.26 \\
\hline 3 & The ability to update the religious knowledge of student-teachers & 5.08 \\
\hline 4 & $\begin{array}{l}\text { Familiarity with the religious objectives of student-teacher curricula in } \\
\text { Farhangian University }\end{array}$ & 5.07 \\
\hline 5 & The ability to recognize the religious needs of students & 4.89 \\
\hline 6 & Familiarity with new religious concepts related to the professors' specialization & 4.88 \\
\hline 7 & $\begin{array}{l}\text { The ability to transfer religious ideas and values and to inspire strong faith in } \\
\text { Islam }\end{array}$ & 4.86 \\
\hline 8 & The ability to maintain the spirit of Islamic knowledge in teaching & 4.76 \\
\hline 9 & Familiarity with the basics and principles of Islamic education & 4.55 \\
\hline
\end{tabular}

According to Table 3 , the $1^{\text {st }}, 2^{\text {nd }}$, and $3^{\text {rd }}$ subscales have scored the highest mean values in order. 
3.4 Research Question 4: What are the educational needs of Farhangian University's faculty members in the domain of "ethical, cultural and social issues"?

Four sub-issues (See table 1) are identified and categorized in relation to this domain.

\subsubsection{Needs in the Cultural Domain}

3.4.1.1. Familiarity with the role of university professors in preserving, transferring, reforming, and recreating culture.

15 interviewees (78.94\%) explicitly emphasized this need and believed that education is necessary for this purpose. Interviewee 4 believed that professors must look at education from a sociological perspective and seriously consider the role of transferring, preserving, reforming and recreating culture. Professors must have a cultural Prospect Document and help to preserve and comply with current cultural values (Interviewee 9). It is essential to consider two main points in the cultural domain: 1. the presence of rich cultural resources based on religious concepts, and 2. developing a form of cultural engineering. Indeed, cultural engineering is necessary prior to any cultural activity. The first step in this regard is to determine the roles of each cultural institution (interviewee 13).

3.4.1.2. Basic familiarity with the humanities (sociology, history, art, philosophy and social science).

One of the main tasks of faculty members is to be familiar with the humanities. This need was emphasized by 9 interviewees (47.36). Interviewee 9 believed that it is necessary for a professor to be familiar with cultural values, principles, and customs in order to be influential in training student-teachers.

\subsubsection{Familiarity with comparative education in order to study other cultures.}

7 interviewees (36.84 percent) emphasized the need for becoming familiar with different cultures in the cultural domain. In fact, comparative education must be taught as a pivotal course in Farhangian University (Interviewee 10). If student-teachers must acquire certain merits in the cultural domain, then one of the best solutions is to prepare the situation by providing teachers with appropriate education (Interviewee 16, Mehrmohamadi, 2013).

\subsubsection{The need for internationalizing the curricula.}

Seven respondents (36.84 percent) pointed to this need. According to interviewee 6 , the internationalization phenomenon facilitates expression for different cultures. In this regard, universities can present their religious teachings and local and cultural values in the field of education, compare themselves to other universities in terms of resources, and meet the educational needs of professors using local resources and the positive achievements of others. 
3.4.1.5. Familiarity with the principles and objectives of cultural direction in Iran's Ministry of Education's Fundamental Development Prospect Document.

As one of the main concerns of the present study, achieving Iran's Ministry of Education's Fundamental Development Prospect Document was emphasized by 12 interviewees (63.15 percent). According to interviewee 11, the basis for teachers' education must be the principles and objectives of cultural direction as stipulated in Iran's Ministry of Education's Fundamental Development Prospect Document. Interviewee 13 also believed that there is the need for a unified cultural management in order not to limit cultural decisions to individuals. Besides, cultural decisions require people who are familiar with modern ways of thinking.

\subsubsection{Recognizing and exposing the signs of cultural invasion.}

13 respondents $(68.42 \%)$ considered this issue as a current educational need of university professors. According to interviewee 2, considering fast socio-cultural transformations, wide global connections, and cultural invasion against the Islamic Republic of Iran, university professors must be alarmed and prepared against this threat.

3.4.1.7. The ability to adjust the educational content of textbooks with religious and cultural resources.

15 interviewees (78.94\%) emphasized this issue. According to interviewee 13, university courses have to be precisely adjusted to the local culture and religious resources since most professors are used to gaining their knowledge from translated books.

3.4.1.8. Familiarity with the objectives of student-teacher curricula in cultural, social, and educational issues

12 interviewees (63.15\%) emphasized this issue. According to interviewee 16, special attention must be paid to Farhangian University's teacher-student training programs. This can in turn inspire professors with ideas. Professors are thus expected to be familiar with the objectives of the curricula (Mehrmohamadi, 2013).

\subsubsection{Needs in the Social Domain}

According to interviewees, four needs comprise the main educational needs of faculty members in this domain, including:

\subsubsection{Recognizing the mission of Farhangian University as a major center for education}

Recognizing the mission of Farhangian University requires special consideration according to 11 respondents $(57.89 \%)$. According to interviewee 3, a university professor must first of all be aware of the university's missions (in relation to education, research, preparing human work force and entrepreneurship), second of all believe in exercising these missions, and third of all consider him/herself as the medium and executor of these missions. Of course, skillfulness in the field of education is one of the main responsibilities of Farhangian University's professors. 
3.4.2.2. Familiarity with the new socio-cultural needs and concerns of students

Eight interviewees (42.10\%) emphasized this educational need. According to interviewee 6, a lack of connection between course contents and current social problems is a big challenge to educational programs. According to interviewee 7, professors must be aware of the young generation's current concerns and consider them in teaching.

\subsubsection{Familiarity with the role of professors in the social growth of student-teachers}

11 interviewees (57.89\%) emphasized this need. According to interviewees 8 and 11, Farhangian University's professors must be aware of social principles and their own role in the social growth of students. According to interviewee 9, the most appealing professors are those who are most aware of current social issues. Also according to interviewee 17, social principles and relations must be presented as a course to students by Farhangian University.

\subsubsection{Familiarity with current social problems and newly formed social phenomena}

Nine interviewees $(47.36 \%)$ emphasized this need. In fact, professors must have a scholarly approach to social issues and pathologies. Their awareness of such issues can result in the awareness of student-teachers, students, families, and subsequently the whole society (Interviewee 12).

\subsubsection{Needs in the Ethical Domain}

According to interviewees, four needs comprise the main educational needs of faculty members in this domain, including:

\subsubsection{Familiarity with the lives of exemplary figures}

10 Interviewees $(52.63 \%)$ believed that familiarity with the lives of exemplary figures can be effectively beneficial in teaching culture. In this regard, we can make use of exemplars as a Quranic method of education (Interviewee 14). According to interviewee 3, we must incorporate a combination of materials on exemplary figures, values, and customs into the curricula and make it available to university professors.

3.4.3.2. Familiarity with the practical lifestyle of Prophet Muhammad, Fatima bint Muhammad, and the twelve Imams (pbut)

10 interviewees $(52.63 \%)$ believed that it is necessary for university professors to become aware of the practical lifestyle of Prophet Muhammad, Fatima bint Muhammad, and the twelve Imams (pbut). In this line, interviewee 4 stated that being a teacher means to transfer not only knowledge but also love. Although it is necessary for a teacher to have rapport, it is more important for him or her to act ethically and be inherently motivated to educate.

\subsubsection{The need for teaching practical educational ethics and principles to teachers}

According to 13 interviewees $(68.42 \%)$, teaching ethical educational behaviors practically is another need of faculty members. They believed that a neglected concept not by teachers but by the entire society is practical ethics. For example, if a teacher teaches about hygiene, he would better teach relevant practical ethics in relation to the environment too, that is, 
incorporate the teachings found in the lifestyle of Prophet Muhammad, Fatima bint Muhammad, Imam Ali, and the other Imams (pbut) (Interviewees 7 and 9). Besides, indirect education would be more effective in the field of training ethics (Interviewee 14).

\subsubsection{The need for teaching educational norms and values:}

Eight interviewees (42.10\%) emphasized this educational need. According to interviewee 15, a university professor must pose as a model or exemplar for his or her students. Furthermore, honesty, professional integrity, respect for people's rights, and familiarity with the factors that foster vitality and mental health in students are the most prior educational needs.

\subsubsection{Needs in the Political Domain}

In this domain, three needs are acknowledged as the most important educational needs of faculty members, including:

\subsubsection{Being aware of political issues (political thinking and understanding)}

Being aware of political issues is another educational need of Farhangian University's faculty members which is emphasized by 11 interviewees (57.89\%). According to interviewee 1, political awareness becomes possible through the teaching of primary Islamic resources including Nahjolbalaghe in the sense that it contains Imam Ali's explication of various political issues.

3.4.4.2. The ability to analyze current issues in Iran and the world in order to answer the questions of student-teachers.

This need is emphasized by 10 interviewees (52.63\%). Farhangian University's faculty members play a very critical role in this regard since they are the educators of Iran's next generation of teachers (Interviewee 2). It is expected that university professors have a political view of their own since having a political view means personal interest in the future of one's own country (Interviewee 4).

\subsubsection{Recognizing the role of professors in the political training of student-teachers}

Nine interviewees $(47.26 \%)$ emphasized the professors' awareness of their role in the political training of student-teachers as a pivotal educational need. According to interviewee 9, Farhangian University's professors must know about and efficiently perform their critical role in the political education of students.

3.5 Research question 5: To what extend do Farhangian University's faculty members require training in the domain of "ethical, cultural and social issues"? 
Table 4. Comparison of the mean need of Farhangian University's faculty members for receiving training in the domain of "ethical, cultural and social issues" with a hypothetical mean value equal to three

\begin{tabular}{|l|l|l|l|l|l|l|}
\hline Factor & Mean & $\begin{array}{l}\text { Standard } \\
\text { deviation }\end{array}$ & $\begin{array}{l}\text { Mean } \\
\text { deviation }\end{array}$ & t & df & Sig \\
\hline $\begin{array}{l}\text { The need for receiving training in } \\
\text { the domain of "ethical, cultural } \\
\text { and social issues" }\end{array}$ & 3.61 & 0.80 & 0.067 & 9.178 & 141 & 0.001 \\
\hline
\end{tabular}

According to table 4, the mean need of Farhangian University's faculty members for receiving training in the domain of ethical, cultural and social issues is equal to 3.61. Since the calculated $t$ value is higher than the criterion $t$ value, the need for receiving training in this domain can be assessed as higher than average.

3.6 Research question 6: What are the most important needs of Farhangian University's faculty members in the domain of "ethical, cultural and social issues"?

Table 5. The most important needs of Farhangian University's faculty members in the domain of "ethical, cultural, social issues"

\begin{tabular}{|l|l|l|}
\hline & Questions & Mean \\
\hline 1 & $\begin{array}{l}\text { Familiarity with the role of university professors in preserving, transferring, } \\
\text { reforming, and recreating culture. }\end{array}$ & 6.08 \\
\hline 2 & Familiarity with the principles and methods of soft war & 5.80 \\
\hline 3 & Recognizing and exposing the signs of cultural invasion. & 5.79 \\
\hline 4 & $\begin{array}{l}\text { The ability to adjust the educational content of textbooks with religious and } \\
\text { cultural resources }\end{array}$ & 5.79 \\
\hline 5 & Familiarity with socio-cultural principles in Islamic education & 5.59 \\
\hline 6 & Familiarity with ethical principles and teaching manners in Islamic education & 5.43 \\
\hline 7 & $\begin{array}{l}\text { Familiarity with the principles and objectives of cultural direction in Iran's } \\
\text { Ministry of Education's Fundamental Development Prospect Document. }\end{array}$ & 5.23 \\
\hline 8 & $\begin{array}{l}\text { Basic familiarity with the humanities (sociology, history, art, philosophy and } \\
\text { social science). }\end{array}$ & 5.14 \\
\hline 9 & $\begin{array}{l}\text { Familiarity with the objectives of student-teacher curricula in cultural, social, } \\
\text { and educational issues. }\end{array}$ & 5.14 \\
\hline 10 & Familiarity with comparative education in order to study other cultures. & 5.02 \\
\hline
\end{tabular}

According to Table 5, all the subscales in the domain of "ethical, cultural, social issues" have scored higher than average. Besides, the $1^{\text {st }}, 2^{\text {nd }}, 3^{\text {rd }}$, and 4 th subscales have scored the highest mean values in order. 


\section{Discussion, Conclusion, and Suggestions}

One of the strategic objectives of Iran's Ministry of Education's Fundamental Development Prospect Document is to revise and reform the curricula based on a cultural-educational approach and to develop and improve the educational and ethical condition of learners based on the Islamic-Iranian culture (Iran's Ministry of Education's Fundamental Development Prospect Document, 2011). Besides, the 20 Years Prospect Document of Islamic Republic of Iran (2003) emphasizes Iran's development by passing from the current developing status in proportion to the cultural, social, and historical conditions of the country and by focusing on ethical principles as well as on national and Islamic values. Paying attention to the essential mission of universities as the most important centers for attaining cultural independence is a very critical and important role for all academicians especially for those who work at Farhangian University. To this end, the main objective of the study is to analyze and explain the cultural, educational, and social needs of Farhangian University's faculty members. In parallel with the research questions, the findings of the study are presented as follows.

Responding to the first research question, the interviewees identified six educational needs of Farhangian University's faculty members (Table 1). It is worth mentioning that the religious needs identified in this study are consistent with the findings of studies by Mirzaee (2002), Rabbani (2003), Shamshiri (2008), and Kazemi (2010). Although these findings confirm the entirety of religious beliefs and emotions in the academia, they represent the growth of a new mode of religious thinking that seeks to undermine the role of religion in society. Besides, one of Iran's educational system's points of weakness in the field of cultural education is inconsistency between Islamic, historical, geographical, and international identities. The results also indicate that despite the efforts of Islamic Republic of Iran's Ministry of Education after the revolution, not much success has been achieved and the performance of educational planners has led nowhere (63). According to the results mentioned above, all of which demonstrate weak performance in the field of religious education, it seems that the educational needs identified in this study are essential to Farhangian University's faculty members. In relation to the second research question, the results show that the mean need of faculty members for receiving religions training is higher than average and equal to 3.61 (Table 2).

Besides, in relation to the third research question, the results presented in table 4 shows that the highest mean scores relate in order to the subscales of "the ability to apply educational methods and implications existing in the Quran and Nahjolbalaghe" and "the need for learning the Quran in order to answer the questions of student-teachers" - representing the highest needs of faculty members. Considering the importance of the issue, it is suggested that Farhangian University develops an educational major for Nahjolbalaghe and train Nahjolbalaghe teachers. In addition, after reviewing the existing literature, interviewing the participants, and collecting data via questionnaires, the researchers concluded that it is necessary for universities to make students internalize the religious and cultural values, attitudes, and norms required by the society and the next generation and make them faithful to Iran's religious and cultural heritage. These objectives are achievable by empowering 
university professors and paying attention to their educational needs via constant and effective education.

Responding to the fourth research question, the interviewees identified four educational needs in the field of ethical, cultural, and social issues, including a) cultural needs, b) social needs, c) ethical needs and d) political needs (Table 1). It is worth noting that the results of the interviews in this part are compatible with the results of studies by Mahdavi (1999), Tavakolinik (1941), Rabbani (2003), Movahedi (2004), Fathi Vajargah (2004), Loqmannia (2009), Loqmannia and Khamesan (2010), Vahed Chukadeh (2005), Jang (2009), and Rivelli (2010).With a look at these results, it becomes evident that there are many cultural problems among the young generation. Therefore, it is suggested that development strategies and patterns be compatible with the local culture of the country. In addition, it is suggested that higher education institutes teach cultural values in a cohesive way. "The need for internationalizing the curricula" is another educational need identified in this study which is consistent with the results of the study by Colleen and Jang (2005) because internationalizing the curricula in universities creates special cultural and educational opportunities for individuals. "Political thinking and understanding" is another educational need identified in this study which is consistent with the results of the study by Rivelli (2010) because imparting political, social, and cultural knowledge to students is deeply correlated with current educational methods in schools and universities.

In relation to the fifth and sixth research questions, the mean need of Farhangian University's faculty members in the domain of "ethical, cultural, and social issues" is higher than average and equal to 3.6 (Table 4). The most important need of faculty members in this regard relates to "familiarity with the role of university professors in preserving, transferring, reforming, and recreating culture" (Table 5). The results of studies by Zokaee (2003), Hamidi (2005), Vahed Chukadeh (2005), Esmaeeli and Rabiee (2008), Osareh et al. (2012), Lee Kuang Wu (2000), Terry Green (2008) and Brandon Bartram (2009) also show that the majority of university students regard socio-educational needs as essential to higher education.

With this in mind, how should higher education perform its critical role in the field of cultural education? Evidence shows that higher education centers must constantly play their role as the agents for maintaining, transferring, reforming, recreating and improving culture among students in order to prepare the ground for efficiency, growth, and development in the country. But what are the tasks and missions of universities, especially Farhangian University, in relation to the current cultural issues of society. As the community of scholars and elites, higher education centers can play an effective role in the cultural mission of the country and in compliance with the Islamic-Iranian identity.

In conclusion, based on the results of conducted studies in the field, mere education is pointless; rather, education is also inclusive of cultural education. After reviewing the existing literature, interviewing the participants, and collecting data via questionnaires, the researchers concluded that educational planners must have convincing reasons for developing cultural and educational plans and programs. Identifying and explaining educational needs before providing any solution can increase the efficiency of educational programs in 
universities which is possible though scientific needs assessment. In order to improve the cultural identity of student-teachers and to emphasize the national, religious, and cultural dimension of education in the curricula, Farhangian University needs to make learners internalize religious values and beliefs by developing educational objectives including the maintenance of our national, religious, cultural, and historical identity through the identification of cultural and educational needs and the development of efficient programs.

\section{Acknowledgement}

Conducted under the auspices and the support of Farhangian University, this study has been extracted from a $\mathrm{PhD}$ thesis.

\section{References}

Ahmadi, kh. Habibi, M. Suri, F. Bigdeli, Z. Nabipour, \& Asbrafi, S.M. (2008). A comparison of cultural and social vulnerability between girls and boys. Iranian Journal of Behavioral Sciences, 2(3), 221-230.

Bartram, B. (2009). The Socio Cultural Needs of International Students in Higher Education: A Comparison of Staff and Student Views.

Beuckelaer,A.D., Lievens, F., \& Bücker, J. (2012). The Role of Faculty Members' Cross-Cultural Competencies in Their Perceived Teaching Quality: Evidence from Culturally-Diverse Classes in Four European Countries. The Journal of Higher Education, 83(2), 217-248. http://dx.doi.org/10.1353/jhe.2012.0007

Blo“meke, S., \& Kaiser, G. (2012). Homogeneity or heterogeneity? Profiles of opportunities to learn in primary teacher education and their relationship to cultural context and outcomes. ZDM Mathematics Education, 44, 249-264. http://dx.doi.org/10.1007/s11858-011-0378-6

Campbell, A., McNamara, O., \& Gilory, P, (2004).Practitioner research and professional development in education, PaulChapman Publishing.

Chalabi, M. (1996). Order Sociology. Tehran: Ney publication.

Chukadeh Vahed, S. (2005). Citizenship and cultural education necessity for civic. Master's thesis. Tabriz University.

Creswell, J. (2007). Qualitative inquiry and research design: Choosing among five approaches, Thousand Oaks:Sage.

Creswell, J., \& Plano Clark, V. (2007). Designing and conducting mixed methods research, Thousand Oaks:Sage.

Delanty, G. (2007) Challenging Knowledge: The University in the Knowledge Society. Translated by Ali Bakhtiyarzadeh. Tehran: cultural social research studies center.

Iran's Ministry of Education's Fundamental Development Prospect Document. (2011). Passed by Supreme Council of the Cultural Revolution in October 2011.

The By-law on Promotion of Faculty Members of Universities and Higher Education, 
Research, and Technology Institutes (2011), Iran's Ministry of Science, Research, and Technology.

Esmaeeli, R., \& Rabiee, K. (2008). Studying socio-cultural needs of female students in Isfahan city. Iranian Women's Socio-Cultural Counsel, 1(41), 98-134.

Fathi Vajargah, K. Ashtiani, \& Dozi Sorkhabadi, M., (2006). Considering citizenship values in the curriculum for teaching in elementary schools. Educational Innovation Quarterly, 17(5), 32-45.

Gharibi, A., (2012). An analysis of general and verbal needs of Persian language learners. Journal of teaching the Persian language via other languages, 1 (1):61-78.

Gutek, G.L., (2011). Philosophical and Ideological Voices in Education, Translated by MohammadJafar Pakseresht, Tehran: Samt

Haghighi, A.M,(2009). Study the role of culture in the sustainable development; a case study of Iranian culture. Cultural Engineering, 4(37\&38), 76-86.

Hamidi, F. (2005). A comparative analysis of the physical, emotional, social and religious needs of teenagers in deprived regions based on gender, Tehran University's Center for Women's Studies, 2(3), 179-159.

Jang, J. Y. (2009). Analysis of the Relationship between Internationalization and the Quality of Higher Education. A dissertation submitted faculty of the Graduate School of the University of Minnesota.

Kazemi, S. Mahram, B., (2013). An analysis of the performance of educational management as a hidden component of curriculum designed for teaching values. Iranian Journal of Curriculum Studies, 5(17), 35-48.

Loqmannia, M. (2009). Identifying elements of national identity in curricula by applying theory-driven approaches, MA Thesis, Faculty of Literature and Humanities, University of Birjand.

Loqmannia, M. \& Khamesan, A. (2010). The status of national identity in Iran's educational system. Cultural Studies Quarterly, 3(2), 147-171.

Mahdavi, M.S. (1999). Cultural pathology of Shahid Beheshti University students. Research Unit, Shahid Beheshti University.

Mason, I. (2002). Linking qualitative and quantitative data analysis, In:A. Bryman \& R. Burgess (Eds.).Analyzing qualitative data, New York: Routledge.

Mehrmohamadi, M. (2013). An Interview with Dr. Mehrmohamadi on the Educational Needs of Farhangian University's Faculty Members, Tehran: March 9, 2014.

Mirzaee, H, (2002). Analyzing the cultural attitudes of Tabriz University day students and some related factors, MA thesis, Faculty of Humanities and Social Sciences, University of Tabriz. 
Monafi Sharafabad, K. \& Zamani, E. (2013). The role of higher education in cultural engineering, Iranian Journal of Cultural Engineering, 77(8), 58-72.

Movahedi, M, (2004). Determining the characteristics of an Iranian-Islamic culture (with an emphasis on their relation to development), Research Plan Report, Supreme Council of the Cultural Revolution.

Noaparast Bagheri, Kh, \& Khosravi, Z. (2011). Deconstructive Religious Education. Religious Education, 106(1), 82-104. http://dx.doi.org/10.1080/00344087.2011.539449

Noy, C. (2008). Sampling knowledge:The hermeneutics of snowball sampling in qualitative research, International Journal of Social Research Methodology, 11(4), 327-344. http://dx.doi.org/10.1080/13645570701401305

Onwuegbuzie, A. J., \& Leech, N. L, (2007). Sampling designs in qualitative research:Making the sampling process more public. The Qualitative Report, 12(2), 238254.

Osareh, A.R, Seraj Khorrami, N. Boroomand Nasab, M. \& Hazineh, N. (2012). Identifying the cultural, educational, and research needs of Islamic Azad University students. Irnanian Journal of New Findings in Human Sciences, 7(21), 47-64.

Plano Clark, V., Creswell, J., O’Neil Green, D., \& Shope, R. (2008). Mixing quantitative and qualitative approaches:An introduction toemergent mixed methods research, In:S. HesseBiber\& P. Leavy. (Eds.). Handbook of emergent methods, New York:The GuilfordPress

Rabbani, J. (2003). Curricula and identiyy formation. Mashhad University's Journal of Psychology and Education Sciences, 4(1), 650-677.

Ran, An, \& Edward, Viv. (2006). Meeting the Needs of Chinese students in British Higher Education. South China University of Technology.

Reyhner, W.S. Gilbert \& L. Lockard (Eds.), (2011). Honoring Our Heritage:Culturally Appropriate Approaches for Teaching Indigenous Students.(pp. 43-55). Flagstaff, AZ:Northern Arizona University.

Reyhner, W.S. Gilbert, \& L. Lockard (Eds.). (2011). Honoring Our Heritage:Culturally Appropriate Approaches for Teaching Indigenous Students (pp. 1-9). Flagstaff, AZ:Northern Arizona University.

Rivelli, S. (2010). Citizenship education at high school A comparative study between Bolzano and Padova (Italy). Free University of Bolzano- Bozen- Faculty of education, Viale Ratisbona 16, Bressanone 39042. Procedia Social and Behavioral Sciences, 2, 4200-4207. http://dx.doi.org/10.1016/j.sbspro.2010.03.664

Russell, L. R. Kinuthia, W. L. Vega, Winnie Tsang-Kosma, \& A.L. Madathany,R. (2013). Identifying complex cultural interactions in the instructional design process:a case study of a cross-border, cross-sector training for innovation program. Education Tech Research Dev., 61, 707-732. http://dx.doi.org/10.1007/s11423-013-9291-8 


\section{Macrothink

Saboktakin, Q.A., \& Khosrojari, Z. (2013). Culture, language and education. Cultural Studies and Communication Quarterly, 30, 55-62.

Safaee, L., \& Borumandfar, S. (2013). Knowledge-based culture as the prerequisite for development and innovation in higher education. National Conference on Development and Innovation in Higher Education, with an emphasis on Fars Province's characteristics. Shiraz.

Shamshiri, B. (2008). An introduction to national identity. Shiraz: Navid publication.

Sharafi, M., \& Taherpour, Z. (2008). The role of education institutions in training citizens. Cultural Engineering Magazine, Supreme Council of the Cultural Revolution (15-16), 23-42.

Sharifian, F, Mirshah Jafari, S.E., Sharif, M., \& Moosapour, N. (2012). Curricula specialists' and graduate students' perspectives on student participation in curriculum definiton. Iranian Journal of New Approaches to Educational, 8(1), 47-88.

Svec, L. (2014). Cultural heritage training in the US military. Springer Plus 2014, 3, 126. http://dx.doi.org/10.1186/2193-1801-3-126

Taherpour, F.; Rajaipour, S.; and Shahbazi, Z. (2009) Analyzing the Organizational Structure of Teacher Training Centers and Public Universities of Isfahan Province. Iranian Journal of Management Outlook, 30, 160-180.

Tavakkoli Nik, K. (2004). An analysis of Tehran's secondary school students' attitude toward cultural invasion and cultural resistance strategies. Research Plan Report, Tehran's Research Cente's Council.

Vahed Chodkeh, S. (2005). Citizenship and cultural education as a prerequisite for urban life, MA thesis, University of Tabriz

Waters, R. (2010). Model for Supporting the Spiritual Development of Students in State Secondary Schools. McClelland College Melbourne, Australia.

Williams, R, (2000). Towards a Cultural Sociology. Translated by Ali Mortazavian. Arghavan Magazine, 18.

Zarchi, R.R., \& Ranamah, A. (2009). Study the relation of globalization and religious education. Cultural Engineering, 4(37\&38.), 22-37.

Zokaee, M.S. (2003). Citizenship education. Youth Studies Quarterly, 19, 58-51. 